\title{
Large-Swing-Tolerant ESD Protection Circuit for Gigahertz Power Amplifier in a 65-nm CMOS Process
}

\author{
Chun-Yu Lin, Member, IEEE, Shiang-Yu Tsai, Li-Wei Chu, Student Member, IEEE, and \\ Ming-Dou Ker, Fellow, IEEE
}

\begin{abstract}
The signal swing at output pad of some radio-frequency (RF) power amplifiers (PAs) may be higher than the supply voltage. To protect the gigahertz large-swing power amplifier from electrostatic discharge (ESD) damage in nanoscale CMOS process, a large-swing-tolerant ESD protection circuit is presented in this paper. The proposed ESD protection circuit had been designed, fabricated, and characterized in a $65-\mathrm{nm}$ CMOS process, where it can achieve low parasitic capacitance, large swing tolerance, high ESD robustness, and good latchup immunity. The proposed ESD protection circuit had been further applied to a 2.4-GHz PA to provide 3-kV human-body-model (HBM) ESD robustness without degrading the $\mathrm{RF}$ performances.
\end{abstract}

Index Terms-Electrostatic discharge (ESD), power amplifier (PA), radio-frequency (RF), silicon-controlled rectifier (SCR).

\section{INTRODUCTION}

$\mathbf{W}$ ITH the potential for mass production, CMOS technologies have been used to implement radio-frequency (RF) circuits. The RF circuits realized in CMOS technologies are susceptible to electrostatic discharge (ESD) events that may damage the IC products. Therefore, on-chip ESD protection circuits must be added at the RF transceiver that may be stressed by ESD, including the input pads of low-noise amplifier (LNA) and the output pads of power amplifier (PA) [1]-[4]. Of course, adding ESD protection circuit causes RF performance degradation with several undesired effects [5], [6]. Parasitic capacitance of the ESD protection device is one of the most important design considerations for RF circuits. A typical specification for a gigahertz RF circuit on human-body-model (HBM)/machine-model (MM) ESD robustness and the maximum parasitic capacitance of ESD protection device are $2 \mathrm{kV} / 200 \mathrm{~V}$ and $200 \mathrm{fF}$, respectively [6]-[9]. The conventional double-diode ESD protection scheme with $\mathrm{D}_{\mathrm{P}}$ (from input/output pad to $\mathrm{V}_{\mathrm{DD}}$ ) and $\mathrm{D}_{\mathrm{N}}$ (from

Manuscript received July 27, 2012; revised October 25, 2012; accepted November 07, 2012. Date of publication December 13, 2012; date of current version February 01, 2013. This work was supported in part by Taiwan Semiconductor Manufacturing Company (TSMC), in part by National Science Council, Taiwan, under Contract NSC 101-2221-E-009-141, and in part by the "Aim for the Top University Plan" of National Chiao Tung University and Ministry of Education, Taiwan.

C.-Y. Lin, S.-Y. Tsai, and M.-D. Ker are with the Institute of Electronics, National Chiao Tung University, Hsinchu, Taiwan (e-mail: cy.lin@ieee.org; mdker@ieee.org).

L.-W. Chu is with the Department of Photonics and Display Institute, National Chiao Tung University, Hsinchu, Taiwan.

Color versions of one or more of the figures in this paper are available online at http://ieeexplore.ieee.org.

Digital Object Identifier 10.1109/TMTT.2012.2231426

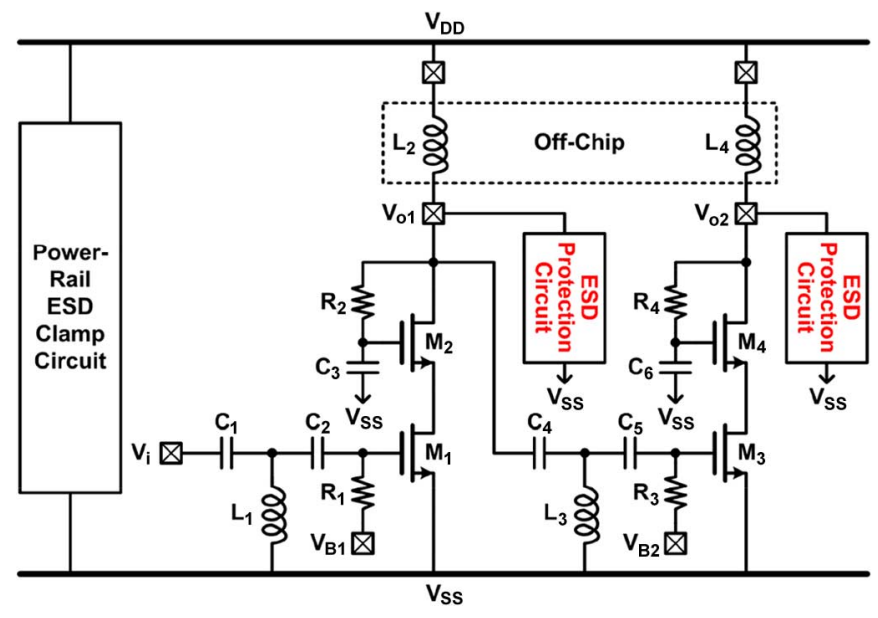

Fig. 1. Power amplifier with ESD protection design.

$\mathrm{V}_{\mathrm{SS}}$ to input/output pad) has been generally used for gigahertz RF circuits, since it can meet the typical specification on ESD robustness and parasitic capacitance [1], [3]. The silicon-controlled rectifier (SCR) device has also been reported to be useful for RF ESD protection [3], [10], [11].

For some PAs, the signal swing at output pad may be as high as two to three times the supply voltage $\left(\mathrm{V}_{\mathrm{DD}}\right)$. The conventional double-diode or SCR ESD protection designs with a diode from output pad to $\mathrm{V}_{\mathrm{DD}}$ limits the maximum signal swing at RF output. Therefore, the PA needs large-swing-tolerant ESD protection circuit at its output pad, as shown in Fig. 1. Compared with high-voltage-tolerant ESD clamp circuits used for mixed-voltage I/O buffers [12]-[14], the large-swing-tolerant ESD protection circuit used for RF PA should also be carefully designed. To implement the ESD protection for the PA without limiting the maximum signal swing, some ESD protection designs have been presented. Some PAs have been realized with on-chip ESD protection inductors in their output matching network [4], [15]. For the PAs without on-chip ESD protection inductors [16], [17], a diode string between output pad and $\mathrm{V}_{\mathrm{DD}}$ could be used [18], as shown in Fig. 2. Of course, this technique is adverse to ESD protection because the overall turn-on resistance and the clamping voltage of the diode string during ESD stresses are increased as well.

In this work, a novel large-swing-tolerant ESD protection circuit is proposed for effective ESD protection on gigahertz PA. This design can achieve low parasitic capacitance, large swing tolerance, high ESD robustness, and good latchup immunity. 


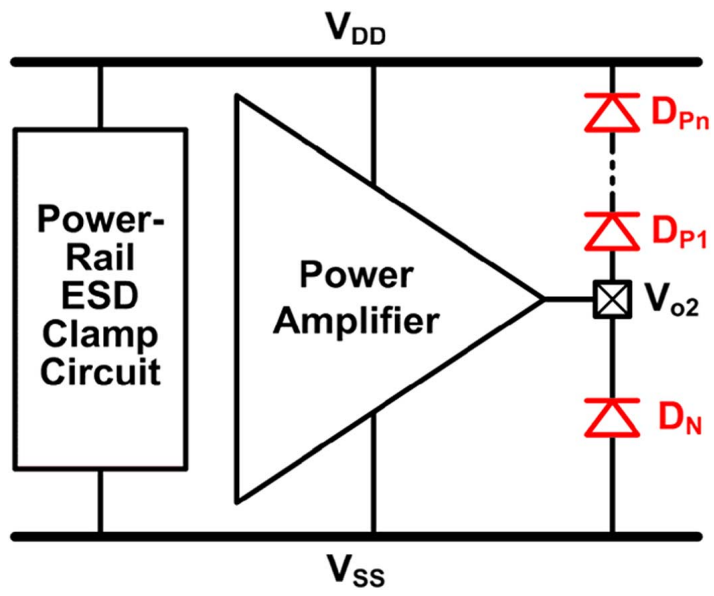

Fig. 2. Conventional ESD protection circuit.

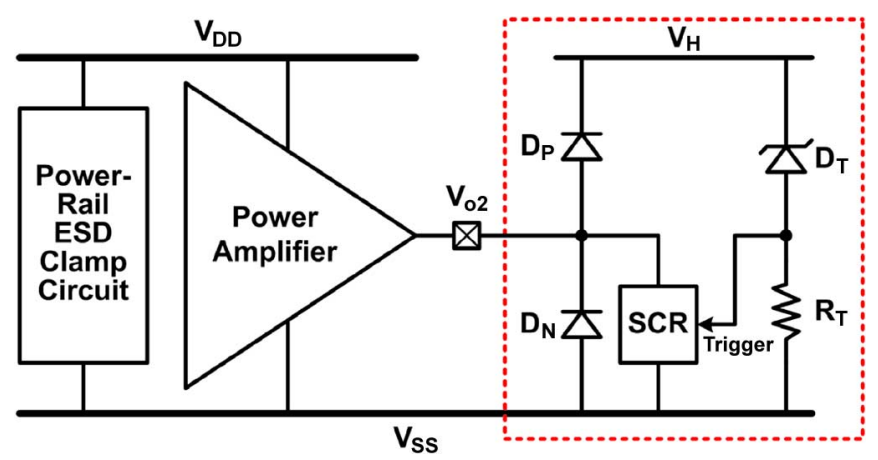

Fig. 3. Proposed ESD protection circuit.

\section{DESIGN OF PROPOSED ESD PROTECTION CiRCUIT}

The new proposed ESD protection circuit utilizes diodes and an SCR as main ESD-current-discharging paths. The proposed ESD protection circuit is shown in Fig. 3, which consists of a P-type diode $\left(\mathrm{D}_{\mathrm{P}}\right)$, a high-voltage node $\left(\mathrm{V}_{\mathrm{H}}\right)$, an N-type diode $\left(D_{N}\right)$, an $S C R$, a trigger diode $\left(D_{T}\right)$, and a trigger resistor $\left(R_{T}\right)$. The $\mathrm{D}_{\mathrm{N}}$ and SCR provide the ESD paths between $\mathrm{V}_{\mathrm{o} 2}$ and $\mathrm{V}_{\mathrm{SS}}$. The power-rail ESD clamp circuit is used to provide the ESD paths between $V_{D D}$ and $V_{S S}$. The $V_{H}$ is an internal node, so the protection between $V_{H}$ and $V_{D D}$ is not needed. The proposed ESD protection circuit can also be used at $V_{\mathrm{o} 1}$ pad.

The equivalent circuit of the SCR consists of the cross-coupled PNP and NPN BJTs. As ESD stresses from anode to cathode of the SCR are applied, the positive-feedback regenerative mechanism of PNP and NPN BJTs results in the SCR device becoming highly conductive to make the SCR very robust against ESD stresses [19]. However, the stand-alone SCR device has a drawback of higher turn-on voltage. To reduce the turn-on voltage, the trigger signal can be sent into the base terminal of the NPN BJT of SCR device. Once ESD stresses from anode to cathode of the SCR, the $\mathrm{D}_{\mathrm{P}}$ and $\mathrm{D}_{\mathrm{T}}$ will turn on first, and then the $\mathrm{R}_{\mathrm{T}}$ will generate a high voltage to trigger the SCR.

While positive ESD charges stress to $\mathrm{V}_{\mathrm{o} 1}$ or $\mathrm{V}_{\mathrm{o} 2}$ with grounded $\mathrm{V}_{\mathrm{SS}}$ (PS mode), the trigger signal is sent through the forward-biased $\mathrm{D}_{\mathrm{P}}$, reverse-breakdown $\mathrm{D}_{\mathrm{T}}$, and $\mathrm{R}_{\mathrm{T}}$ to enhance the turn-on efficiency of SCR, and the ESD currents can be discharged through the SCR. As positive ESD charges stress to

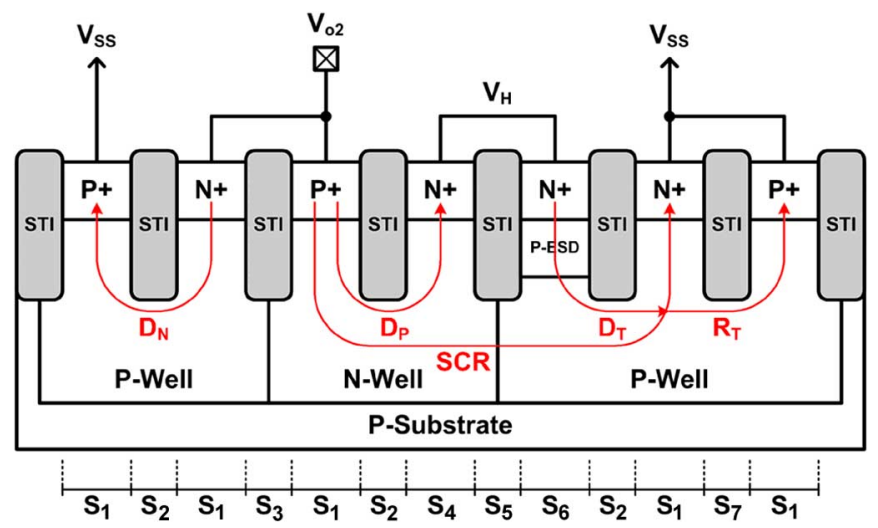

Fig. 4. Cross-sectional view of test circuit.

$\mathrm{V}_{\mathrm{o} 1}$ or $\mathrm{V}_{\mathrm{o} 2}$ with grounded $\mathrm{V}_{\mathrm{DD}}$ (PD mode), the ESD currents can be discharged through the SCR to the floating $\mathrm{V}_{\mathrm{SS}}$, and then through the power-rail ESD clamp circuit to $V_{D D}$. While negative ESD charges stress to $V_{\mathrm{o} 1}$ or $V_{\mathrm{o} 2}$ with grounded $V_{S S}$ (NS mode), the ESD currents can be discharged through the forward-biased $D_{N}$. As negative ESD charges stress to $V_{o 1}$ or $\mathrm{V}_{\mathrm{o} 2}$ with grounded $\mathrm{V}_{\mathrm{DD}}$ (ND mode), the ESD currents can be discharged through the forward-biased $\mathrm{D}_{\mathrm{N}}$ to the floating $\mathrm{V}_{\mathrm{SS}}$, and then through the power-rail ESD clamp circuit to $V_{D D}$. As ESD charges stress between $V_{01}$ and $V_{02}$ (pin-to-pin mode), the ESD currents can be discharged through the first SCR and the second forward-biased $D_{N}$. The proposed ESD protection circuit in Fig. 3 can provide the corresponding ESD paths.

Under normal RF circuit operating conditions, the $\mathrm{V}_{\mathrm{H}}$ node is charged and kept at a high voltage by the output swing of the power amplifier; therefore, the $\mathrm{D}_{\mathrm{P}}$ is kept off. Besides, the $\mathrm{D}_{\mathrm{N}}$ and SCR are also kept off to prevent from the signal loss.

To realize the proposed design in silicon chip, a cross-sectional view of test circuit is shown in Fig. 4. All the components used in the proposed design are embedded in this structure. The $\mathrm{D}_{\mathrm{P}}$ and $\mathrm{D}_{\mathrm{N}}$ are realized by $\mathrm{P}+/ \mathrm{N}$-well and $\mathrm{N}+/ \mathrm{P}$-well junctions, respectively. The SCR path consists of $\mathrm{P}+, \mathrm{N}$-well, $\mathrm{P}$-well, and $\mathrm{N}+$. The $\mathrm{D}_{\mathrm{T}}$ is realized by $\mathrm{N}+\mathrm{P}-\mathrm{ESD}$ junction, where the P-ESD denotes the p-type ESD implantation [20]. The $R_{T}$ is realized by the P-well resistor.

The dimensions of the test circuits are labeled as $\mathrm{S}_{1}, \mathrm{~S}_{2}, \mathrm{~S}_{3}$, $\mathrm{S}_{4}, \mathrm{~S}_{5}, \mathrm{~S}_{6}$, and $\mathrm{S}_{7}$. The $\mathrm{P}+/ \mathrm{N}$-well and $\mathrm{N}+/ \mathrm{P}$-well junctions in the main ESD-current-discharging paths of $\mathrm{D}_{\mathrm{N}}$ and SCR should be wide enough, so the $S_{1}$ is selected to $0.8 \mu \mathrm{m}$. The turn on voltage of SCR is mainly determined by the breakdown voltage of $\mathrm{D}_{\mathrm{T}}$. The test circuits with different dimensions are split to investigate the characteristics of the proposed ESD protection circuit, including the parasitic capacitance, ESD robustness, turn on voltage, and holding voltage. In the test circuit A, the dimensions are arranged as $\mathrm{S}_{1}=0.8 \mu \mathrm{m}, \mathrm{S}_{2}=0.3 \mu \mathrm{m}, \mathrm{S}_{3}=0.3 \mu \mathrm{m}$, $\mathrm{S}_{4}=0.2 \mu \mathrm{m}, \mathrm{S}_{5}=0.3 \mu \mathrm{m}, \mathrm{S}_{6}=0.4 \mu \mathrm{m}$, and $\mathrm{S}_{7}=1 \mu \mathrm{m}$. In the test circuits B, C, D, E, F, and G, the dimensions are changed to $\mathrm{S}_{2}=1 \mu \mathrm{m}, \mathrm{S}_{3}=1 \mu \mathrm{m}, \mathrm{S}_{4}=1 \mu \mathrm{m}, \mathrm{S}_{5}=1 \mu \mathrm{m}, \mathrm{S}_{6}=1 \mu \mathrm{m}$, and $\mathrm{S}_{7}=0.5 \mu \mathrm{m}$, respectively. The device width $(\mathrm{W})$ of the test circuits are kept at $40 \mu \mathrm{m}$, which is estimated to pass 2-kV HBM and 200-V MM ESD tests. All these dimensions of test circuits are listed in Table I. 
TABLE I

Design Parameters and Measurement Results of Test Circuits

\begin{tabular}{|c|c|c|c|c|c|c|c|c|}
\hline & \multicolumn{7}{|c|}{ Test Circuits } \\
\hline & & A & B & C & D & $E$ & $\mathbf{F}$ & G \\
\hline \multirow{8}{*}{$\begin{array}{l}\text {.0 } \\
\frac{0}{8} \\
\text { 口. }\end{array}$} & $\mathrm{S}_{1}(\mu \mathrm{m})$ & \multicolumn{7}{|c|}{0.8} \\
\hline & $S_{2}(\mu \mathrm{m})$ & 0.3 & 1 & \multicolumn{5}{|c|}{0.3} \\
\hline & $\mathrm{S}_{3}(\mu \mathrm{m})$ & \multicolumn{2}{|c|}{0.3} & 1 & \multicolumn{4}{|c|}{0.3} \\
\hline & $S_{4}(\mu \mathrm{m})$ & \multicolumn{3}{|c|}{0.2} & 1 & \multicolumn{3}{|c|}{0.2} \\
\hline & $\mathrm{S}_{5}(\mu \mathrm{m})$ & \multicolumn{4}{|c|}{0.3} & 1 & \multicolumn{2}{|c|}{0.3} \\
\hline & $S_{6}(\mu \mathrm{m})$ & \multicolumn{5}{|c|}{0.4} & 1 & 0.4 \\
\hline & $\mathrm{S}_{7}(\mu \mathrm{m})$ & \multicolumn{6}{|c|}{1} & 0.5 \\
\hline & $W(\mu \mathrm{m})$ & \multicolumn{7}{|c|}{40} \\
\hline \multirow{6}{*}{ 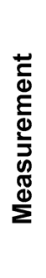 } & Parasitic Capacitance at $2.4 \mathrm{GHz}$ (fF) & 75.7 & 74.6 & 73.4 & 75.3 & 74.8 & 77.6 & 75.3 \\
\hline & HBM ESD Robustness (kV) & 3.25 & 3.25 & 3.25 & 3 & 3.25 & 3 & 3 \\
\hline & MM ESD Robustness (V) & 200 & 200 & 225 & 175 & 200 & 200 & 175 \\
\hline & $\operatorname{TLP} V_{t 1}(V)$ & 8.04 & 8.65 & 8.08 & 8.25 & 7.99 & 7.97 & 8.18 \\
\hline & $T L P I_{\mathrm{t} 2}(\mathrm{~A})$ & 1.76 & 1.82 & 1.76 & 1.66 & 1.73 & 1.69 & 1.64 \\
\hline & DC V $V_{\text {hold }}(V)$ & 2.52 & 3.11 & 2.37 & 3.61 & 3.1 & 3.07 & 2.79 \\
\hline
\end{tabular}

\section{EXPERIMENTAL RESUltS OF PROPOSED ESD PROTECTION CIRCUIT}

The test circuits have been fabricated in a $65-\mathrm{nm}$ salicided CMOS process without using the silicide-blocking mask. To facilitate the on-wafer RF measurement, these test circuits are arranged with ground-signal-ground (G-S-G) style in layout.

\section{A. Parasitic Capacitance}

With the on-wafer measurement, the two-port S-parameters of the test circuits were measured by using the vector network analyzer. The source and load resistances to the test circuits are kept at $50 \Omega$. In order to extract the intrinsic characteristics of the test circuits in high frequencies, the parasitic effects of the G-S-G pads have been removed by using the de-embedding technique [21]. The parasitic capacitance of each test circuit can be extracted from the S-parameters. Fig. 5 shows the extracted parasitic capacitance of the test circuits from 0 to $20 \mathrm{GHz}$. The intrinsic parasitic capacitances of the test circuits are about 75 $\mathrm{fF}$ at $2.4 \mathrm{GHz}$.

\section{B. ESD Robustness}

The HBM and MM ESD robustness of the test circuits are evaluated by the ESD tester. The failure criterion is defined as the $\mathrm{I}-\mathrm{V}$ curve seen between test pads shifting over $30 \%$ from its original curve after ESD stressed at every ESD test level. In other words, the leakage current under $\mathrm{V}_{\mathrm{DD}}$ bias $(2.5 \mathrm{~V}$, in this work) will not increase over $30 \%$ if the test circuit is not failed after ESD stresses. The test circuits A, B, C, D, E, F, and G have about 3-kV HBM and about 200-V MM ESD robustness.

To investigate the turn-on behavior and the I-V characteristics in high-current regions of the ESD protection circuits, the transmission-line-pulsing (TLP) system with 10-ns rise time and 100-ns pulse width is used. The TLP-measured I-V characteristics are shown in Fig. 6. The trigger voltages $\left(V_{t 1}\right)$ of the test circuits are about $8 \mathrm{~V}$, which means the ESD protection circuit can sustain up to $8-\mathrm{V}$ signal swing. The secondary

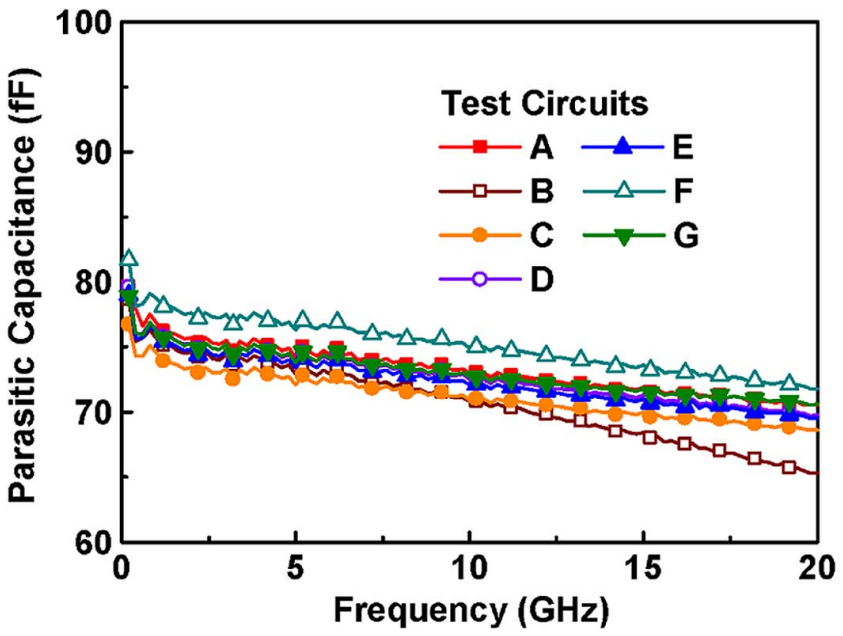

Fig. 5. Parasitic capacitance of test circuits.

breakdown current $\left(\mathrm{I}_{\mathrm{t} 2}\right)$ of ESD protection circuit, which indicated the current-handling ability, can also be obtained from the TLP-measured I-V curve. All test circuits can achieve the $I_{t 2}$ of about 1.7-A.

\section{Latchup Immunity}

The de I-V curves of the test devices are shown in Fig. 7. The holding voltages $\left(\mathrm{V}_{\text {hold }}\right)$ of the ESD protection circuits under dc measurement are lower than those under TLP measurement due to the self-heating effect [22]. The test circuits B, D, E, F, and $\mathrm{G}$ exhibit de $\mathrm{V}_{\text {hold }}$ larger than $\mathrm{V}_{\mathrm{DD}}(2.5 \mathrm{~V})$ with at least $10 \%$ margin, which are very safe from latchup event. All these measured data are summarized in Table I.

\section{Discussion}

According to the experimental results, most of the test circuits achieve the targets of $2-\mathrm{kV} H B M / 200-\mathrm{V}$ MM ESD robustness 


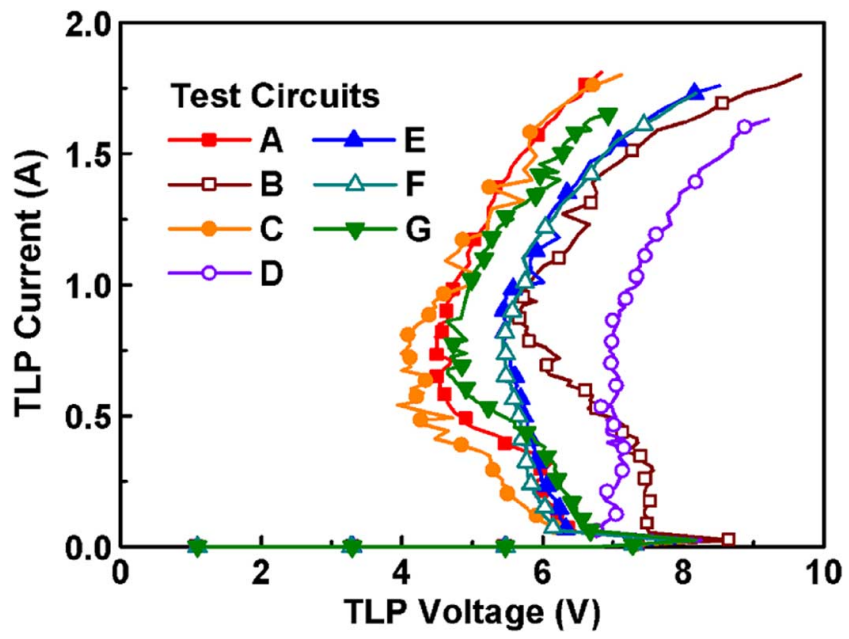

Fig. 6. TLP I-V curves of test circuits.

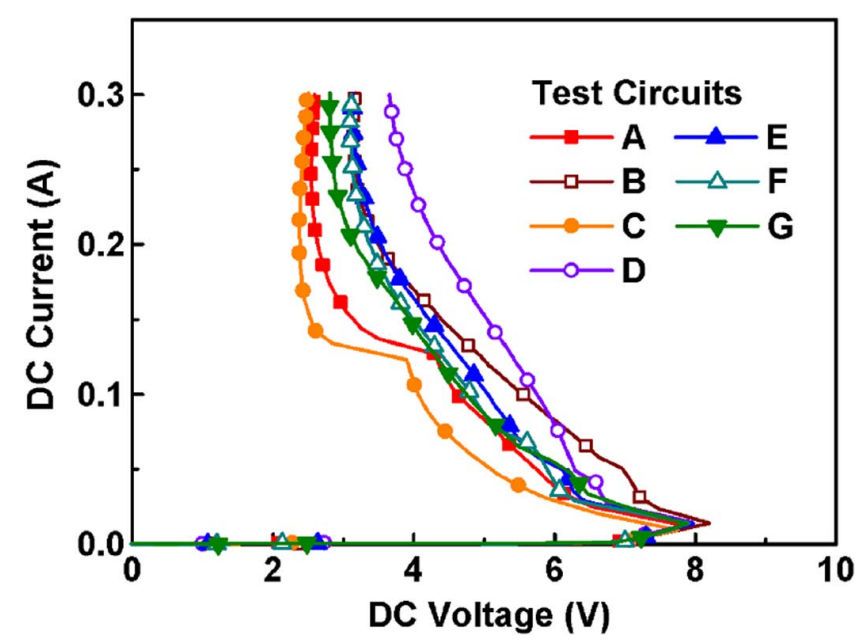

Fig. 7. DC I-V curves of test circuits.

and 8 -V signal swing tolerance with only $\sim 75$-fF parasitic capacitance. Among the test circuits, the test circuit $\mathrm{E}$ with $74.8 \mathrm{-fF}$ parasitic capacitance, $3.25-\mathrm{kV}$ HBM/200-V MM ESD robustness, 7.99-V TLP $\mathrm{V}_{\mathrm{t} 1}, 1.73-\mathrm{A}$ TLP $\mathrm{I}_{\mathrm{t} 2}$, and $3.1-\mathrm{V}$ dc $\mathrm{V}_{\text {hold }}$ is much suitable for ESD protection on the PA.

\section{PA With Proposed ESD Protection Circuit}

The proposed ESD protection circuit has been further applied to the PA shown in Fig. 1. The test circuit $\mathrm{E}$ is selected to protect the $\mathrm{V}_{\mathrm{o} 1}$ and $\mathrm{V}_{\mathrm{o} 2}$ pads of the PA.

\section{A. PA Design and Implementation}

The PA is designed to operate at $2.4 \mathrm{GHz}$ with $\mathrm{V}_{\mathrm{DD}}$ supply of $2.5 \mathrm{~V}$. To sustain large signal swing, the PA utilizes the selfbiased cascade topology [23]. The dimensions of devices used in the PA are listed in Table II. The simulated small-signal gain of the PA is $25 \mathrm{~dB}$. The maximum output power is $23 \mathrm{dBm}$ with a power gain of $30 \mathrm{~dB}$ and a PAE of $34 \%$. The maximum drain voltage of $\mathrm{M}_{4}$ is $5.97 \mathrm{~V}$, and the maximum drain-to-gate and drain-to-source voltages of $\mathrm{M}_{4}\left(\mathrm{M}_{3}\right)$ are $2.28 \mathrm{~V}$ and $3.14 \mathrm{~V}$ $(1.87 \mathrm{~V}$ and $2.83 \mathrm{~V})$, respectively. With the simulated voltage and current waveforms, a reliability simulation result shows the PA can pass the lifetime $>10$ years.
TABLE II

DESIGN PARAMETERS OF POWER AMPLIFIER

\begin{tabular}{|c|c|c|c|}
\hline \multicolumn{2}{|c|}{ 1st Stage } & \multicolumn{2}{c|}{ 2nd Stage } \\
\hline$M_{1}(\mu \mathrm{m} / \mu \mathrm{m})$ & $512 / 0.28$ & $M_{3}(\mu \mathrm{m} / \mu \mathrm{m})$ & $3072 / 0.28$ \\
\hline$M_{2}(\mu \mathrm{m} / \mu \mathrm{m})$ & $512 / 0.28$ & $M_{4}(\mu \mathrm{m} / \mu \mathrm{m})$ & $3072 / 0.28$ \\
\hline $\mathrm{L}_{1}(\mathrm{nH})$ & 5.62 & $\mathrm{~L}_{3}(\mathrm{nH})$ & 1.32 \\
\hline $\mathrm{L}_{2}(\mathrm{nH})$ & 2.80 & $\mathrm{~L}_{4}(\mathrm{nH})$ & 3.32 \\
\hline $\mathrm{C}_{1}(\mathrm{pF})$ & 0.32 & $\mathrm{C}_{4}(\mathrm{pF})$ & 0.60 \\
\hline $\mathrm{C}_{2}(\mathrm{pF})$ & 0.32 & $\mathrm{C}_{5}(\mathrm{pF})$ & 3.33 \\
\hline $\mathrm{C}_{3}(\mathrm{pF})$ & 2.41 & $\mathrm{C}_{6}(\mathrm{pF})$ & 2.41 \\
\hline $\mathrm{R}_{1}(\mathrm{k} \Omega)$ & 5 & $\mathrm{R}_{3}(\mathrm{k} \Omega)$ & 5 \\
\hline $\mathrm{R}_{2}(\mathrm{k} \Omega)$ & 2.5 & $\mathrm{R}_{4}(\mathrm{k} \Omega)$ & 2.5 \\
\hline
\end{tabular}

In some RF applications, the off-chip inductors are used due to the higher inductance and the better quality factor, as the $\mathrm{L}_{2}$ and the $\mathrm{L}_{4}$ used in Fig. 1. To simplify the test environment in this work, the $\mathrm{L}_{2}$ and the $\mathrm{L}_{4}$ are implemented on chip, but they did not directly connect to $V_{D D}$. Additional $V_{D D}^{*}$ pads are used to connect the $\mathrm{L}_{2}$ and the $\mathrm{L}_{4}$ to $\mathrm{V}_{\mathrm{DD}}$ supply under RF measurements, while the $\mathrm{V}_{\mathrm{DD}}^{*}$ pads are floating under ESD tests. This arrangement can simulate the ESD test condition of PA with off-chip inductors.

The PA with and without ESD protection circuits have been fabricated in 65-nm CMOS process. Fig. 8 shows the chip photograph of the ESD-protected PA. The $\mathrm{V}_{\mathrm{o} 1}, \mathrm{~V}_{\mathrm{o} 2}, \mathrm{~V}_{\mathrm{DD}}$, and $\mathrm{V}_{\mathrm{SS}}$ pads are arranged for ESD tests, while the $\mathrm{V}_{\mathrm{i}}$ and $\mathrm{V}_{\mathrm{o} 2}$ pads in G-S-G style and the $V_{D D}^{*}, V_{B 1}$, and $V_{B 2}$ in P-G-P style are arranged for RF measurements. The layout area of each PA is $1000 \times 1100 \mu \mathrm{m}^{2}$, including all pads. In the ESD-protected PA, the proposed ESD protection circuits are added beside the $V_{\mathrm{o} 1}$ and $\mathrm{V}_{\mathrm{o} 2}$ pads, which does not increase the layout area.

\section{B. RF Measurement Results Before ESD Tests}

The RF characteristics are measured on wafer through G-S-G microwave probes. The input and output of PA were matched to $50 \Omega$. Each PA circuit operates with the $2.5-V V_{D D}$ supply and draws a total current of $420 \mathrm{~mA}$. The used bias voltages $V_{\mathrm{B} 1}$ and $\mathrm{V}_{\mathrm{B} 2}$ are all $0.9 \mathrm{~V}$. The measured $\mathrm{S}_{11}$ and $\mathrm{S}_{21}$ parameters of the PAs are shown in Fig. 9. The peak power-gain frequencies of both PAs are shifted to about $2.65 \mathrm{GHz}$. The small-signal gains at $2.65 \mathrm{GHz}$ are about $23 \mathrm{~dB}$ for two PAs. The input return losses for both PAs are about $20 \mathrm{~dB}$ at $2.65 \mathrm{GHz}$. The maximum output power of both PAs are about $22 \mathrm{dBm}$ with power gain of $21 \mathrm{~dB}$ and PAE of $28 \%$. The proposed ESD protection circuit does not degrade the RF performances of the PA.

\section{RF Measurement Results After ESD Tests}

To verify the ESD protection ability of the proposed ESD protection circuit, the RF performances of both PAs after ESD tests are re-measured. All PS, PD, NS, ND, and pin-to-pin modes of HBM ESD stresses are performed to the PAs.

The output power $\left(\mathrm{P}_{\text {out }}\right)$, power gain, and PAE of the PA without ESD protection circuit are severely degraded after $1-\mathrm{kV}$ HBM ESD tests, as seen in Figs. 10-12. In contrast with the unprotected PA, the ESD-protected PA still works after 3-kV HBM ESD tests. The output power, power gain, and PAE of the PA with the proposed ESD protection circuits after HBM ESD tests are shown in Figs. 13-15, respectively. 


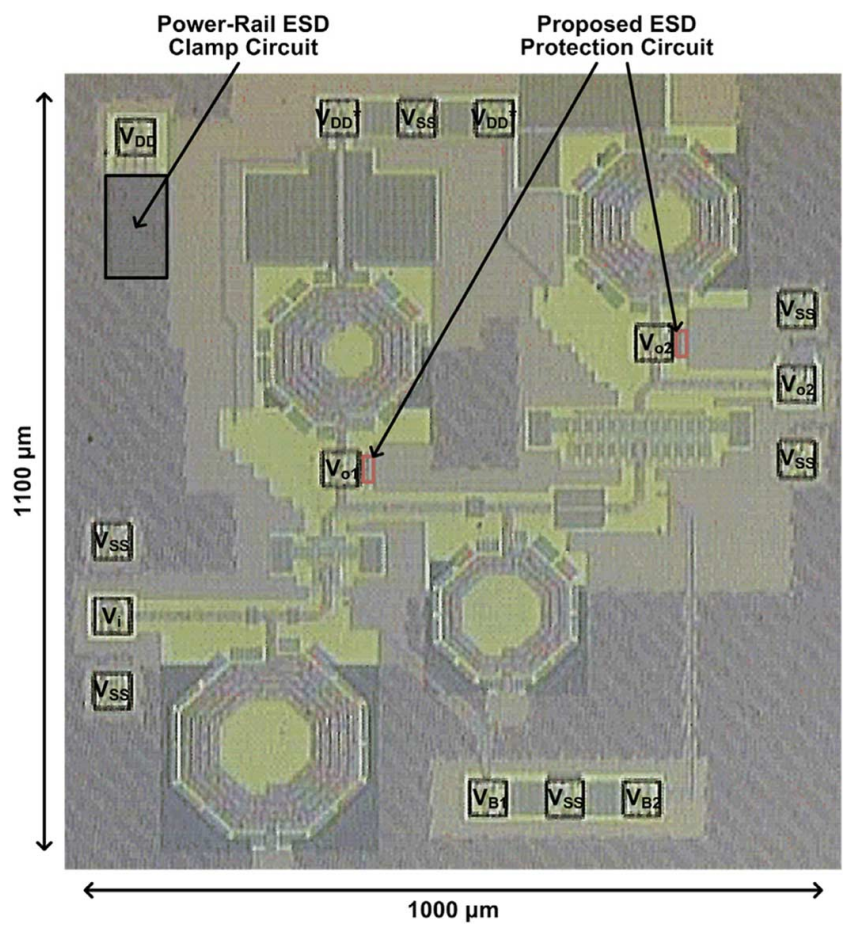

Fig. 8. Chip photograph of PA with proposed ESD protection circuit.

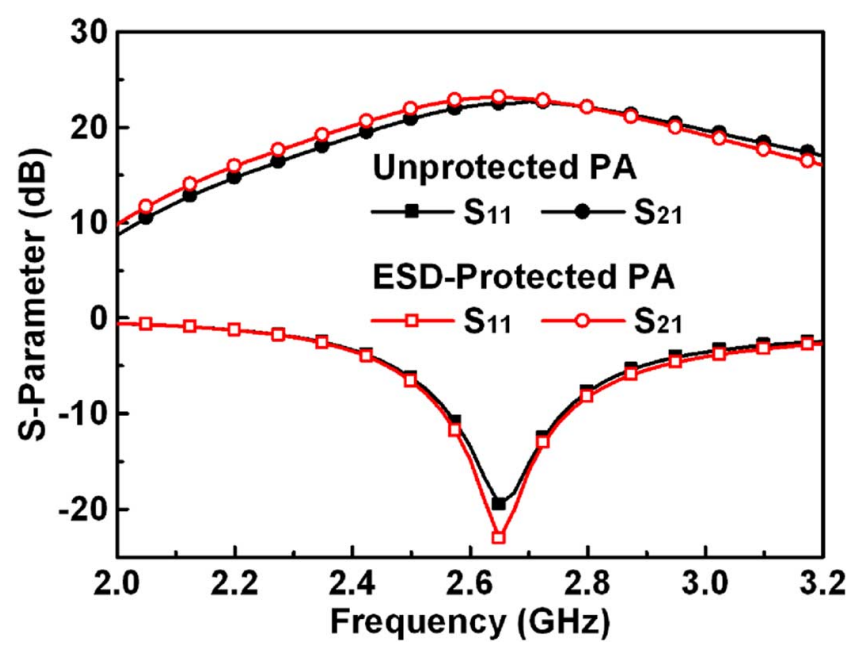

Fig. 9. S-parameters of PA with and without ESD protection circuit.

\section{Very Fast TLP}

To evaluate the effectiveness of the proposed ESD protection circuit in faster ESD-transient events, a very-fast-TLP (VFTLP) system with 0.2 -ns rise time and 1-ns pulse width is used in this study. The VFTLP system can be used to capture the transient behavior of ESD protection circuits in the time domain of charged-device-model (CDM) ESD event [24]. The VFTLPmeasured I-V characteristics of the PA with and without ESD protection circuits are shown in Fig. 16. The proposed ESD protection circuit is fast enough to be turned on under such a fast-transient pulse to improve the ESD robustness.

\section{E. Failure Analysis}

The ESD-protected PA after 4-kV HBM ESD test has failed. Fig. 17 shows the emission microscope (EMMI) analysis of the

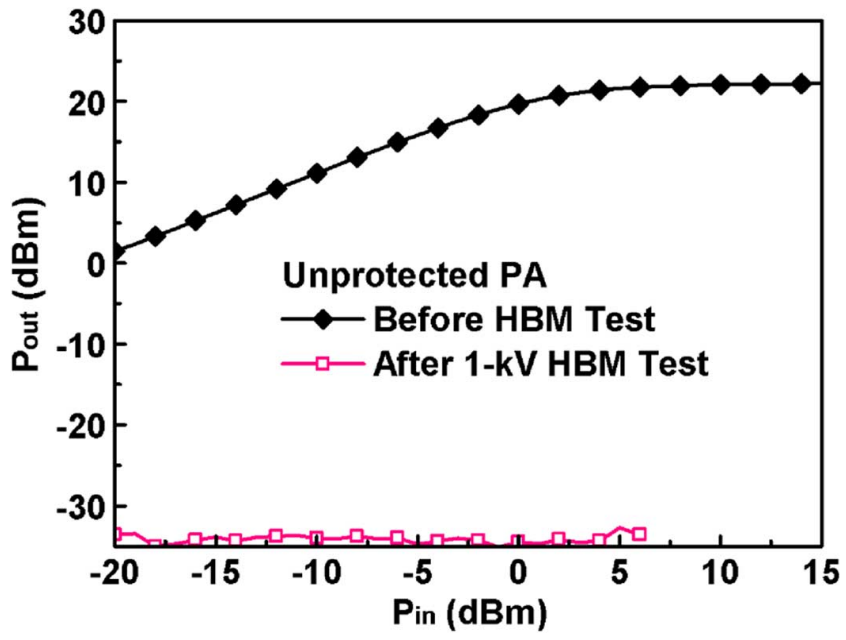

Fig. 10. $\mathrm{P}_{\text {out }}$ versus $\mathrm{P}_{\text {in }}$ of PA without ESD protection circuit.

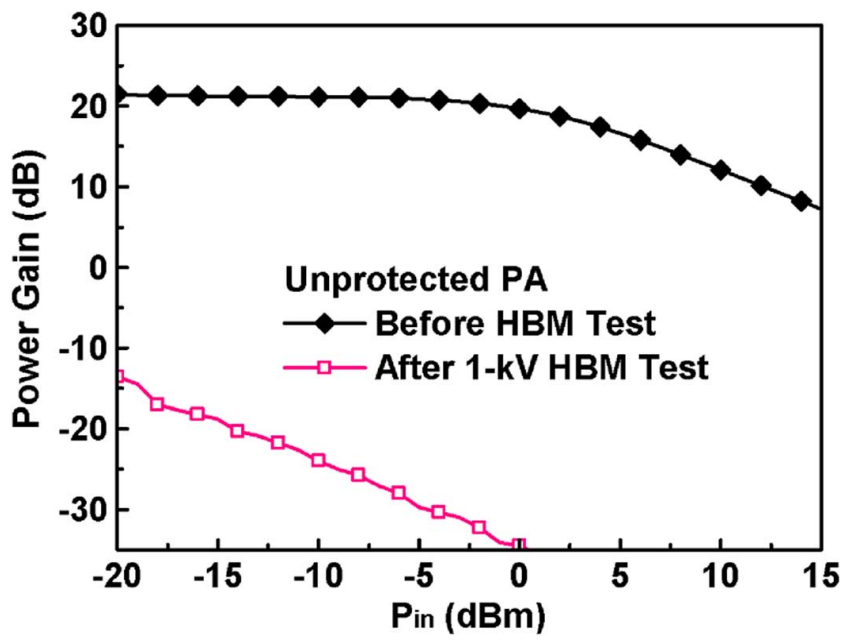

Fig. 11. Power gain versus $\mathrm{P}_{\text {in }}$ of $\mathrm{PA}$ without $\mathrm{ESD}$ protection circuit.

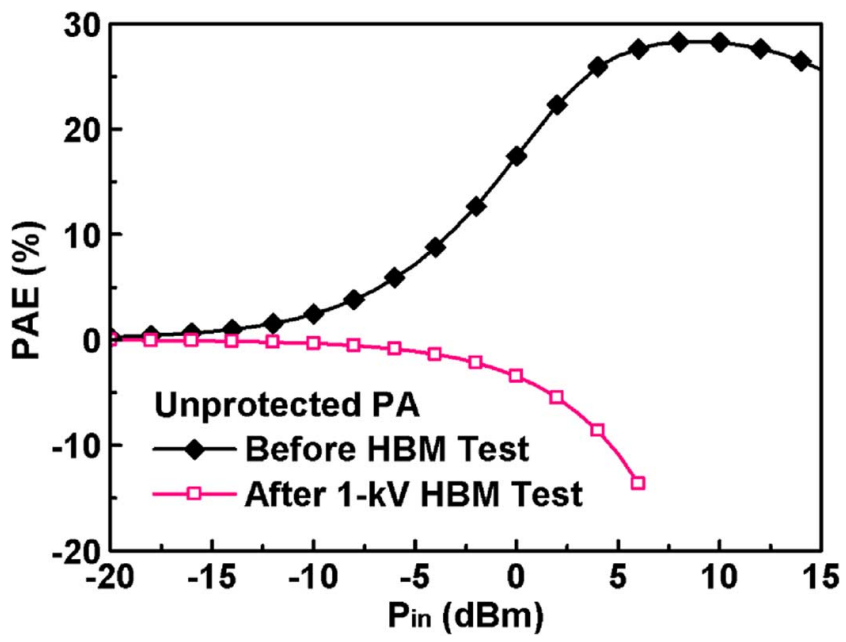

Fig. 12. PAE versus $P_{\text {in }}$ of PA without ESD protection circuit.

PA with new proposed ESD protection circuits after 4-kV HBM ESD tests, where failure location is found in the ESD protection circuit beside $V_{\mathrm{o} 1}$ pad. The proposed ESD protection circuit has 


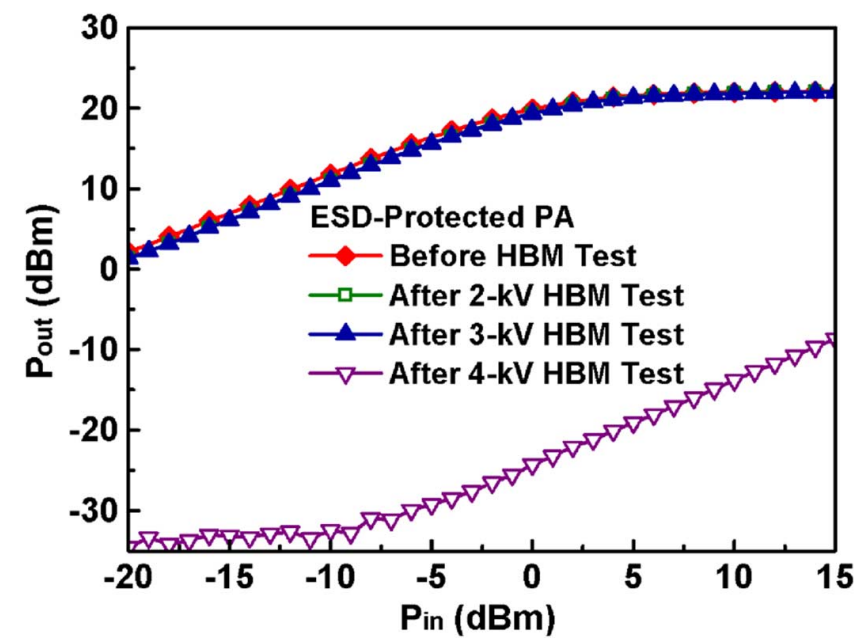

Fig. 13. $\mathrm{P}_{\text {out }}$ versus $\mathrm{P}_{\mathrm{in}}$ of PA with ESD protection circuit.

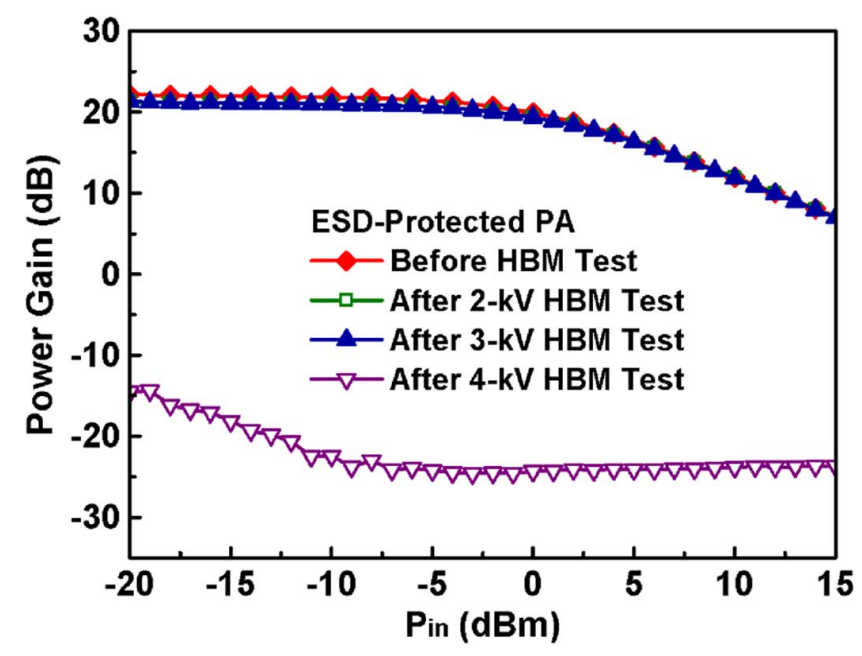

Fig. 14. Power gain versus $P_{\text {in }}$ of PA with ESD protection circuit.

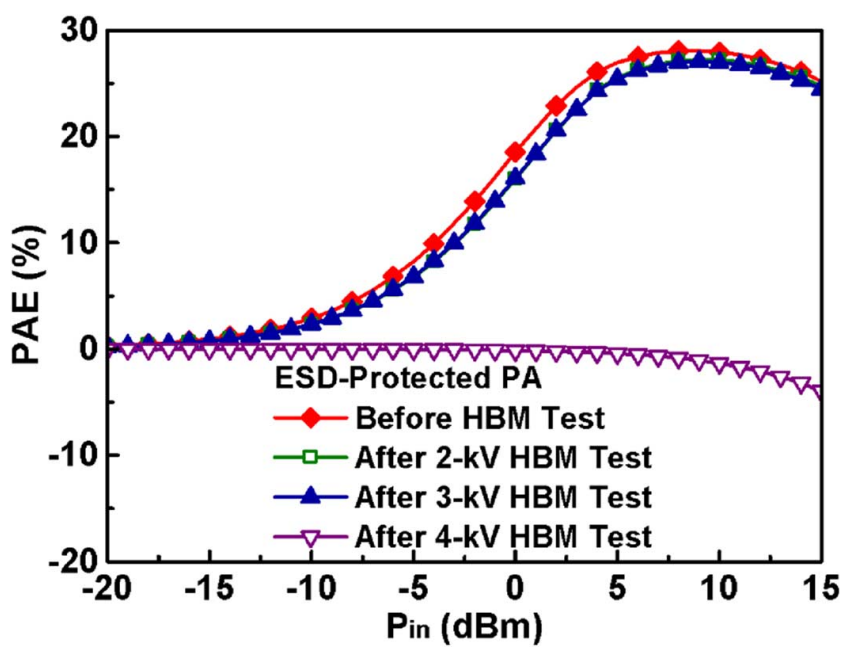

Fig. 15. PAE versus $P_{i_{n}}$ of PA with ESD protection circuit.

been verified to protect the PA from ESD damage with $3-\mathrm{kV}$ HBM ESD robustness.

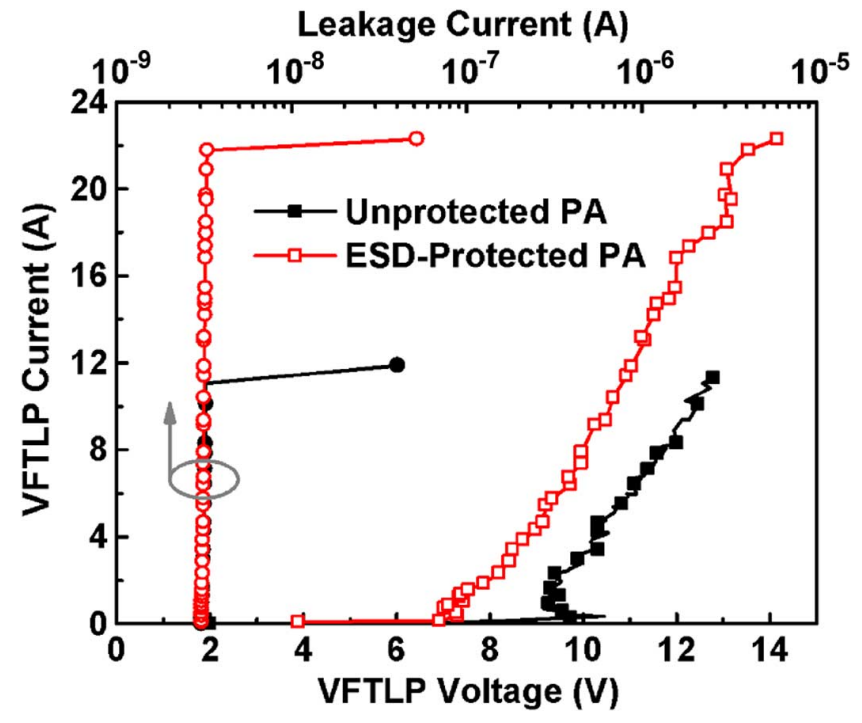

Fig. 16. Very-fast-TLP I-V curves of PA with and without ESD protection circuit.

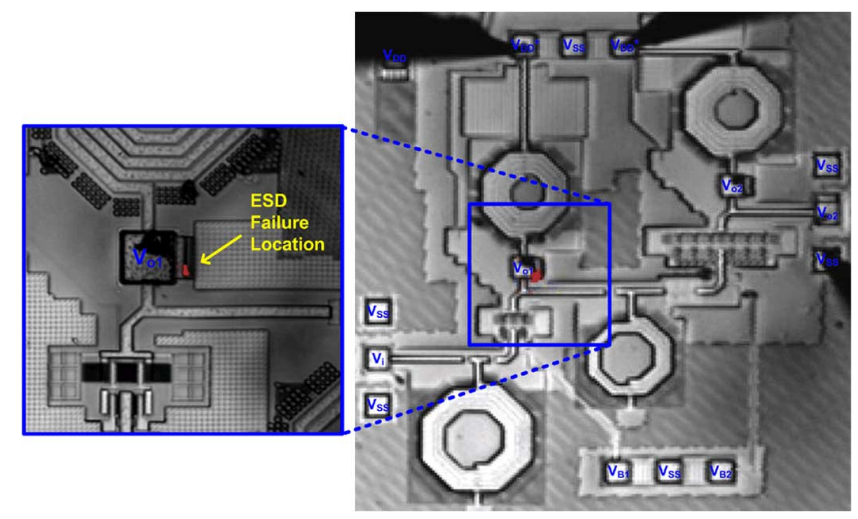

Fig. 17. EMMI photograph to show ESD failure location.

\section{CONCLUSION}

The new ESD protection circuit with low parasitic capacitance, large swing tolerance, high ESD robustness, and good latchup immunity has been developed for the gigahertz power amplifier. The test circuits have been designed, realized, fabricated, and characterized in a $65-\mathrm{nm}$ CMOS process. Seven test circuits with different dimensions have been investigated, in which the test circuit $\mathrm{E}$ with $74.8 \mathrm{-fF}$ parasitic capacitance, 3.25-kV HBM/200-V MM ESD robustness, 7.99-V TLP-measured $\mathrm{V}_{\mathrm{t} 1}, 1.73-\mathrm{A}$ TLP-measured $\mathrm{I}_{\mathrm{t} 2}$, and $3.1-\mathrm{V}$ dc $\mathrm{V}_{\text {hold }}$ has been applied to a 2.4-GHz PA. Measurement results verify the RF performances and confirm the ESD protection ability. The proposed ESD protection circuit provides 3-kV HBM ESD robustness without degrading the RF performances of PA, while the stand-alone PA even cannot sustain 1-kV HBM ESD tests. The proposed ESD protection circuit can be further applied to millimeter-wave power amplifiers, once they can be combined or co-designed.

\section{ACKNOWLEDGMENT}

The authors would like to thank the review meetings of Taiwan Semiconductor Manufacturing Company (TSMC) during circuit design and measurement, where the participants 
included Mr. M.-H. Song, Mr. C.-P. Jou, Mr. T.-H. Lu, Mr. J.-C. Tseng, Mr. M.-H. Tsai, Mr. T.-L. Hsu, Mr. P.-F. Hung, Mr. Y.-L. Wei, and Mr. T.-H. Chang.

\section{REFERENCES}

[1] M. Tsai, S. Hsu, F. Hsueh, and C. Jou, "A multi-ESD-path low-noise amplifier with a 4.3-A TLP current level in 65-nm CMOS," IEEE Trans. Microw. Theory Tech., vol. 58, no. 12, pp. 4004-4011, Dec. 2010.

[2] T. Chang, J. Chen, L. Rigge, and J. Lin, "ESD-protected wideband CMOS LNAs using modified resistive feedback techniques with chip-on-board packaging," IEEE Trans. Microw. Theory Tech., vol. 56, no. 8, pp. 1817-1826, Aug. 2008.

[3] Y.-W. Hsiao and M.-D. Ker, "A 5-GHz differential low-noise amplifier with high pin-to-pin ESD robustness in a 130-nm CMOS process," IEEE Trans. Microw. Theory Tech., vol. 57, no. 5, pp. 1044-1053, May 2009.

[4] K. Raczkowski, S. Thijs, W. Raedt, B. Nauwelaers, and P. Wambacq, "50-to-67 GHz ESD-protected power amplifiers in digital $45 \mathrm{~nm} \mathrm{LP}$ CMOS," in ISSCC Dig. Tech. Papers, 2009, pp. 382-383.

[5] K. Gong, H. Feng, R. Zhan, and A. Wang, "A study of parasitic effects of ESD protection on RF ICs," IEEE Trans. Microw. Theory Tech., vol. 50, no. 1, pp. 393-402, Jan. 2002.

[6] C. Richier, P. Salome, G. Mabboux, I. Zaza, A. Juge, and P. Mortini, "Investigation on different ESD protection strategies devoted to $3.3 \mathrm{~V}$ RF applications $(2 \mathrm{GHz})$ in a $0.18 \mu \mathrm{m}$ CMOS process," J. Electrostatics, vol. 54, no. 1, pp. 55-71, Jan. 2002.

[7] W. Soldner, M. Kim, M. Streibl, H. Gossner, T. Lee, and D. SchmittLandsiedel, "A $10 \mathrm{GHz}$ broadband amplifier with bootstrapped $2 \mathrm{kV}$ ESD protection," in ISSCC Dig. Tech. Papers, Feb. 2007, pp. 550-551.

[8] D. Linten, S. Thijs, M. Natarajan, P. Wambacq, W. Jeamsaksiri, J. Ramos, A. Mercha, S. Jenei, S. Donnay, and S. Decoutere, "A 5-GHz fully integrated ESD-protected low-noise amplifier in 90-nm RF CMOS," IEEE J. Solid-State Circuits, vol. 40, no. 7, pp. 1434-1442, Jul. 2005.

[9] M.-D. Ker, J.-J. Peng, and H.-C. Jiang, "ESD test methods on integrated circuits: An overview," in Proc. IEEE Int. Conf. Electronics, Circuits and Systems, 2001, pp. 1011-1014.

[10] C.-Y. Lin, L.-W. Chu, and M.-D. Ker, "ESD protection design for 60-GHz LNA with inductor-triggered SCR in 65-nm CMOS process," IEEE Trans. Microw. Theory Tech., vol. 60, no. 3, pp. 714-723, Mar. 2012.

[11] M. Mergens, C. Russ, K. Verhaege, J. Armer, P. Jozwiak, R. Mohn, B. Keppens, and C. Trinh, "Speed optimized diode-triggered SCR (DTSCR) for RF ESD protection of ultra-sensitive IC nodes in advanced technologies," IEEE Trans. Device Mater. Rel., vol. 5, no. 3, pp. 532-542, Sep. 2005.

[12] C.-T. Yeh and M.-D. Ker, "New design of $2 \times$ VDD-tolerant powerrail ESD clamp circuit for mixed-voltage I/O buffers in 65-nm CMOS technology," IEEE Trans. Circuits Syst. II, Exp. Briefs, vol. 59, no. 3, pp. 178-182, Mar. 2012

[13] M.-D. Ker and C.-Y. Lin, "High-voltage-tolerant ESD clamp circuit with low standby leakage in nanoscale CMOS process," IEEE Trans. Electron Devices, vol. 57, no. 7, pp. 1636-1641, Jul. 2010.

[14] C.-T. Wang and M.-D. Ker, "Design of $2 \times$ VDD-tolerant power-rail ESD clamp circuit with consideration of gate leakage current in $65-\mathrm{nm}$ CMOS technology," IEEE Trans. Electron Devices, vol. 57, no. 6, pp. 1460-1465, Jun. 2010

[15] Y.-D. Shiu, B.-S Huang, and M.-D. Ker, "CMOS power amplifier with ESD protection design merged in matching network," in Proc. IEEE Int. Conf. Electronics, Circuits and Systems, 2007, pp. 825-828.

[16] C. Chang, P. Wang, C. Tsai, C. Li, C. Chang, H. Shih, M. Tsai, W. Wang, K. Chan, and Y. Lin, "A CMOS transceiver with internal PA and digital pre-distortion for WLAN $802.11 \mathrm{a} / \mathrm{b} / \mathrm{g} / \mathrm{n}$ applications," in Proc. IEEE Radio Frequency Integrated Circuits Symp., 2010, pp. 435-438.

[17] D. Calvillo-Cortes, L. Vreede, and M. Langen, "A compact and powerscalable $70 \mathrm{~W}$ GaN class-E power amplifier operating from 1.7 to 2.6 GHz," in Proc. Asia-Pacific Microwave Conf., 2011, pp. 1546-1549.

[18] M. Ruberto, O. Degani, S. Wail, A. Tendler, A. Fridman, and G. Goltman, "A reliability-aware RF power amplifier design for CMOS radio chip integration," in Proc. IEEE Int. Reliability Physics Symp., 2008, pp. 536-540.

[19] M.-D. Ker and K.-C. Hsu, "Overview of on-chip electrostatic discharge protection design with SCR-based devices in CMOS integrated circuits," IEEE Trans. Device Mater. Rel., vol. 5, no. 2, pp. 235-249, Jun. 2005.
[20] M.-D. Ker, C.-H. Chuang, and W.-Y. Lo, "ESD implantations for on-chip ESD protection with layout consideration in $0.18-\mu \mathrm{m}$ salicided CMOS technology," IEEE Trans. Semicond. Manuf., vol. 18, no. 2, pp. 328-337, May 2005

[21] H. Yen, T. Yeh, and S. Liu, "A physical de-embedding method for silicon-based device applications," PIERS Online, vol. 5, no. 4, pp. 301-305, 2009.

[22] A. Tazzoli, F. Marino, M. Cordoni, A. Benvenuti, P. Colombo, E. Zanoni, and G. Meneghesso, "Holding voltage investigation of advanced SCR-based protection structures for CMOS technology," Microelectron. Rel., vol. 47, no. 9-11, pp. 1444-1449, Sep. 2007.

[23] T. Sowlati and D. Leenaerts, "A 2.4 GHz $0.18 \mu \mathrm{m}$ CMOS self-biased cascode power amplifier," IEEE J. Solid-State Circuits, vol. 38, no. 8, pp. 1318-1324, Aug. 2003.

[24] C. Chu, A. Gallerano, J. Watt, T. Hoang, T. Tran, D. Chan, W. Wong, J. Barth, and M. Johnson, "Using VFTLP data to design for CDM robustness," in Proc. EOS/ESD Symp., 2009, pp. 286-291.

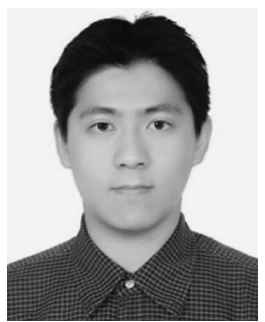

Chun-Yu Lin (S'06-M'09) received the B.S. degree from the Department of Electronics Engineering, $\mathrm{Na}$ tional Chiao Tung University, Hsinchu, Taiwan, in 2006 and the Ph.D. degree from the Institute of Electronics, National Chiao Tung University, in 2009.

$\mathrm{He}$ is currently an Assistant Research Fellow with the Institute of Electronics, National Chiao Tung University. His current research interests include electrostatic discharge protection designs and biomimetic circuit designs.

Dr. Lin has served as the Secretary-General of Taiwan ESD Association since 2010.

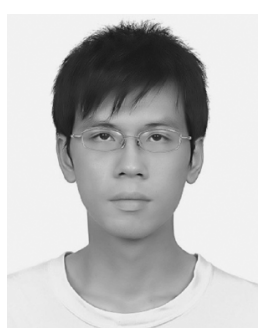

Shiang-Yu Tsai received the B.S. degree from the Department of Electronics Engineering, National Chiao Tung University, Hsinchu, Taiwan, in 2010 and the M.S. degree from the Institute of Electronics, National Chiao Tung University, in 2012.

His current research interests include electrostatic discharge protection designs for radio-frequency circuits.

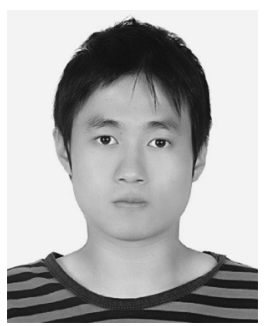

Li-Wei Chu (S'10) received the B.S. degree from the Department of Electrical Engineering, National Sun Yat-sen University, Taiwan, in 2006 and the M.S. and $\mathrm{Ph}$.D. degree from the Institute of Electro-Optical Engineering, National Chiao Tung University, Taiwan, in 2008 and 2012, respectively.

His current research interests include peripheral circuits integrated on panel for flat panel display applications and electrostatic discharge protection designs for radio-frequency and high-speed circuits.

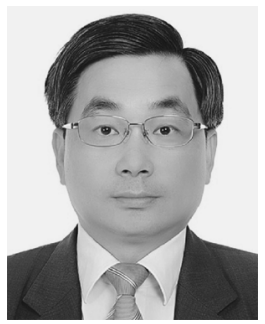

Ming-Dou Ker (S'92-M'94-SM'97-F'08) received the Ph.D. degree from the Institute of Electronics, National Chiao Tung University, Hsinchu, Taiwan, in 1993.

He worked as the Department Manager with the VLSI Design Division, Computer and Communication Research Laboratories, Industrial Technology Research Institute (ITRI), Hsinchu, Taiwan. Since 2004, he has been a Full Professor with the Department of Electronics Engineering, National Chiao Tung University, Hsinchu, Taiwan. During 2008-2011, he was rotated to be Chair Professor and Vice President of I-Shou University, Kaohsiung, Taiwan. Now, he has been the Distinguished Professor in the Department of Electronics Engineering, National Chiao Tung University, Taiwan. Since 2012, he has been the Dean of the College of Photonics, 
National Chiao Tung University, Taiwan. He served as the Executive Director of National Science and Technology Program on System-on-Chip (NSoC) in Taiwan during 2010-2011; and currently is serving as the Executive Director of National Science and Technology Program on Nano Technology (NPNT) in Taiwan (2011-2014). In the technical field of reliability and quality design for microelectronic circuits and systems, he has published over 450 technical papers in international journals and conferences. He has proposed many solutions to improve the reliability and quality of integrated circuits, which have been granted with hundreds of U.S. patents and Taiwan patents. He had been invited to teach and/or to consult the reliability and quality design for integrated circuits by hundreds of design houses and semiconductor companies in the worldwide IC industry. His current research interests include reliability and quality design for nanoelectronics and gigascale systems, circuit-related reliability issue, as well as the biomimetic circuits and systems for intelligent prosthesis.

Prof. Ker has served as a member of the Technical Program Committee and the Session Chair of numerous international conferences for many years. $\mathrm{He}$ served as the Associate Editor for the IEEE TRANSACTIONS ON VLSI SYSTEMS, 2006-2007. He was selected as the Distinguished Lecturer in the IEEE Circuits and Systems Society (2006-2007) and in the IEEE Electron Devices Society (2008-2012). He was the Founding President of Taiwan ESD Association. Starting in 2012, he is currently serving as the Editor of the IEEE TRANSACTIONS ON DEVICE AND Materials Reliability. 